\title{
Financial Agglomeration Level Domain Western Province Based on Principal Component Analysis Measurement
}

\author{
Hongmei Zhang ${ }^{1,2,3}$, Teng $\mathrm{Li}^{2,3}$, Xiangrui Meng ${ }^{1,3}$, Ziyan Wang ${ }^{1,3}$ \\ 1 Guizhou University of Finance and Economics, Guizhou Institution for Technology Innovation \& Entrepreneurship \\ Investment, Guiyang Guizhou 550025, China \\ 2 Guizhou University of Finance and Economics, Guizhou Institution for Urban Economy and Development, Guiyang \\ Guizhou 550025, China \\ 3 Guizhou University of Finance and Economics, School of Finance, Guiyang Guizhou 550025, China
}

\section{基于主成份分析法的西部省域金融集聚水平测度研究 ${ }^{*}$}

\author{
张红梅 $1,2,3$, 李腾 2,3 , 孟祥䒹 1,3 , 王资 1,3 \\ 1. 贵州财经大学贵州科技创新创业投资研究院, 贵州贵阳 550025 \\ 2. 贵州财经大学贵州城镇经济与发展研究院, 贵州贵阳 550025 \\ 3. 贵州财经大学金融学院，贵州贵阳 550025
}

\begin{abstract}
In order to analyze the level of China's western provincial financial agglomeration. In this paper, based on the really situation of western China, by constructing domain Agglomeration Level Measurement of financial evaluation index system of western provinces. using principal component analyze the western 11 provinces sample data, its financial agglomeration levels were more intuitive and objective evaluation. The results show that annual financial Agglomeration 11 western region is relatively stable in 2001-2012. In order to improve the overall financial agglomeration provincial level in western China, the paper points out that different areas should be combined with the construction of differentiated development models, and tap the potential advantages of regional development, thereby increasing the level of financial agglomeration.
\end{abstract}

* 基金项目: 贵州省教育厅高校人文社会科学研究硕士点项 目 (题目: 西部省域生态效率与金融集聚的关联性及耦合协 调发展研究; 编号: 15SSD013)
Keywords: The Region of Western Province; Financial Agglomeration; Principal Component Analysis

\section{摘 要}

为了分析我国西部省域金融集聚的水平。本文结合我 国西部的现实情况, 通过构建西部省域金融集聚水平 测度评价指标体系, 对西部 11 个省样本数据运用主 成分分析方法其金融集聚水平进行了较为直观、客观 的评价。研究结果表明, 2001-2012 年 12 个年度内, 西部 11 个地区的金融集聚程度相对比较稳定。为了 提高我国西部省域整体的金融集聚水平, 本文指出应 结合不同地区的特点构建差异化的发展模式, 挖掘地 区发展的潜在优势, 从而提高地区金融集聚水平。

关键词: 西部省域; 金融集聚; 主成份分析法

1. 引言

自我国在 1999 年 9 月的中共中央第十五届四 中全会上首次提出西部大开发的战略决策构思以 来, 政府先后制定了政策、财政、重点项目开发等 一系列扶持措施以帮助西部省域快速发展。在此之 后, 我国西部经济伴随着 “十五”、“十一五”、“十 
Risk Analysis and Crisis Response in Big Data Era (RAC-16)

二五”计划中相关战略部署的实施落实逐渐步入了

“快车道”。在西部大开发战略实施的过程中, 随 着金融机构的入驻, 西部地区的金融产业开始呈现 出区域集聚的现象。2015 年 “一带一路” 建设顶层 设计规划的出台, 更是将包括新疆、陕西、甘肃、 宁夏、青海、内蒙古、广西、云南、西藏等西部 9 省纳入到战略规划中, 为西部地区经济的发展带来 了前所未有的巨大机遇。

从 20 世纪 70 年代开始, 金融集聚逐渐成为现 代社会中金融产业组织的主流形式。以美国纽约、 英国伦敦和日本东京为代表的国际金融中心在全 世界范围内陆续出现; 而我国国内则陆续出现了以 北京、上海和深圳这三个城市为代表的国内金融中 心。金融集聚是一个各类金融机构、企业及其管理 机构汇集于一处的过程, 并在此过程中逐渐加深国 内外企业机构间联系。从本质上看, 这一过程反映 了金融行业以利益最大化为目标不断发展、改进、 融合的优化途径。

国外金融集聚的形成已有 40 余年历史，国外 学者已经积累下了较为丰厚的研究成果。1974 年 Kindleberger (1974) ${ }^{[1]}$ 最先提出金融集聚的概念。 由于金融集聚这个概念具有异常丰富的内涵，所以 截止到目前理论界还没有给出明确的大众一致认 可的定义。Panditetal (1998，2001) ${ }^{[2]}$ 认为金融服 务业更倾向于向某一区域内集聚并成金融中心，并 针对英国金融业聚集过程分别使用不同模型进行 了实证研究, 结果表明中心内部关系密切且集聚水 平直接影响新进者数量。相比较于国外, 虽然我国 金融集聚的发展较晚, 但学者对其的研究十分活跃。 王力和周波 (2004) ${ }^{[3]}$ 通过研究发现, 金融集聚与区 域经济相辅相成, 互相产生影响。梁颖 (2006) 通过研究得出，要想形成金融产业在某一空间领域 上的集聚, 必须是具有完整业务结构和功能的总部 机构率先进驻该地区, 带来完善的金融服务。而不 仅仅是小规模营业网点的进入。刘军等人 (2007) ${ }^{[5]}$ 认为金融集聚主要通过金融功能、金融集聚效应和 金融扩散效应这三个主要途径来促进实体经济的 增长。黄解宇和杨再斌 (2008) ${ }^{[6]}$ 指出, 一方面, 金 融集聚是各类金融机构、资源在空间范围的聚集; 另一方当面, 其也对产业发展及人民生活起到了促 进作用。滕春强 (2006) ${ }^{[7]}$ 通过理论分析得出, 金融 产业集群的形成是一个动态变化的过程, 具有某些 差异化特征的金融企业通过与当地的产业、环境、 技术进行融合，产生协同效应。一旦当地的投资环
境发生改变, 就会产生金融资源的流动, 寻求新的 平衡状态, 在某一时间点, 达到均衡。另外, 金融 产业集群是具有一定规模的非正式组织, 集群内部 企业彼此没有行政隶属关系, 但又会存在信息、技 术上的沟通。王步芳 (2006) ${ }^{[8]}$ 将金融产业集群理解 为能够满足不同层次的金融需求, 金融服务水平高 度发达的聚集状态。当某一区域内积聚起足够多的 金融机构或部门时, 这个金融集聚体系就会具备金 融市场更加综合化的功能, 在金融资源整合力、产 品服务竞争力、技术人才吸引力和区域市场影响力 方面形成持续强劲的竞争力, 而金融中心是其最终 的一种表现形式。

从相关研究可以看出, 金融集聚是系统中所有 的参与要素在功能结构和层次等级等方面有序演 变的结果, 也是其在时间、空间和文化地理等因素 的影响下相互作用, 互相促进的结果。金融集聚一 方面是静态成果, 如金融机构、产品等; 另一方面, 其也是动态融合进程, 如市场资源优化配置、效率 提高等。在上述分析的基础上, 本文认为: 金融集 聚的过程即为市场中各主体积极探索合作共生发 展的反映, 在这个过程中, 资源配置得到优化并且 形成了健康的合作竞争关系。

\section{2. 指标体系构建与数据}

如何构建一个行之有效的金融集聚评价指标 体系, 是衡量评价结果准确性的关键。马丹 (2007) ${ }^{[9]}$ 根据相关理论, 从经济规模、集聚水平与基础建 设三个方面构建了评价指标体系, 并在此基础上分 析确定 18 个二级指标。丁艺, 李树丞和李林 (2009) ${ }^{[10]}$ 从银行、保险、证券及其整体四个方面构建了指 标体系对金融集聚水平进行评价研究。李静, 白江 (2014) ${ }^{[11]}$ 在研究时将金融市场细分为保险、证券、 信托等子市场, 进而确定指标的选取。

通过对前人的研究结果进行分析总结发现, 在 构建金融集聚指标体系时, 大都遵循了以下三个基 本原则: 可度量性、全面性以及相对性原则。这就 意味着我们在选取指标时, 首先, 所采纳利用的指 标要易于获取且可以度量, 针对那些不可获取或者 是难以度量的指标就采用近似数据来替代, 多采用 定量的指标, 适当的少用或者舍弃一些定性的指标, 以此来保证所构建的指标体系的可操作性和西部 省域间各地方共同比较的客观基础; 其次, 为保证 我国西部省域的金融集聚水平得到充分反映, 须从 各方面出发构建完整全面的指标体系; 第三, 针对 
Risk Analysis and Crisis Response in Big Data Era (RAC-16)

我国西部省域在行政区划面积、地理环境状况、人 口数量和经济发展水平方面存在较大差异的现实 情况，需采用能反映地区间差异的相对化指标进行 分析, 进而更加全面的反映各地区金融集聚水平。 根据上述金融集聚指标选取体系构建的原则，结合
我国西部省域不同地方的经济发展现实状况, 最后 本文从金融集聚动态发展的角度出发, 使用金融行 业整体以及银行、证券、保险行业作为一级指标并 共下设 16 个二级指标, 如表 1 所示:

\begin{tabular}{|c|c|c|}
\hline 目标层 & 一级指标 & 二级指标 \\
\hline \multirow{16}{*}{ 金融集聚 } & \multirow{4}{*}{ 金融总体规模 } & 现金收入 ( 亿元 ) \\
\hline & & 现金支出 ( 亿元 ) \\
\hline & & 金融业增加值（ 亿元） \\
\hline & & 金融业从业人员总数 (人 ) \\
\hline & \multirow{4}{*}{ 银行市场 } & 银行业金融机构各项存款(余额) ( 亿元) \\
\hline & & 银行业金融机构各项贷款(余额) ( 亿元) \\
\hline & & 银行机构数 (个) \\
\hline & & 银行业从业人数（人） \\
\hline & \multirow{3}{*}{ 证券市场 } & 境内外上市公司总数 ( 家 ) \\
\hline & & 股票市价总值 ( 亿元 ) \\
\hline & & 证券营业部数（个） \\
\hline & \multirow{5}{*}{ 保险市场 } & 保费收入 ( 亿元 ) \\
\hline & & 赔款及给付支出 ( 亿元 ) \\
\hline & & 保险密度 ( 元/人 ) \\
\hline & & 保险深度 ( \% ) \\
\hline & & 保险从业人员总数 (人) \\
\hline
\end{tabular}

从本质上来讲, 金融集聚数量庞大的金融机构 聚集、融合的过程，并同时产生了规模经济和外部 效应。金融机构的种类很多，表现形式更是复杂多 样，要想涵盖所有的金融机构是不太现实的，因此
本文就选取了国内三类典型的金融机构的发展情 况加以代表, 它们分别是银行业、保险业和证券业。 其中, 银行业指标下设的二级指标使用了存款额和 贷款额、机构数和从业人数来衡量, 之所以首先选 
Risk Analysis and Crisis Response in Big Data Era (RAC-16)

取银行业金融机构年存、贷款额作为二级衡量指标 主要在于，储蓄是投资主体的资金供给来源，它在 一定程度上能够代表银行业金融机构在将储蓄转 化为投资的过程中可以利用、可以配置的金融资源 的多寊, 它不仅影响着银行业引导配置社会资源的 有效性, 也影响着银行业匹配收益和风险的优化过 程, 进而更是影响着金融集聚本质作用的发挥; 保 费收入、赔款及给付支出、保险深度和保险密度以 及保险业从业人数是反映我国保险业发展情况的 最佳指标, 因此我们就选取这五个二级指标来衡量 保险业的发展情况; 证券业发展情况的反映指标则 选取了境内外上市公司总数、股票市值总值、证券 营业部门数等, 因为在我国证券业发展的过程中政 府的基础资源配置功能作用非同小可，因此采用上 市公司数量是可以反映证券业的发展规模的, 另外, 我国的股票筹资额也可以在某种程度上反映证券 业的资金筹措情况。

在所构建的评价指标体系的基础上，本文以内 蒙古、陕西、宁夏、甘肃、青海、新疆、四川、重 庆、云南、贵州、广西等西部的 11 个省、自治区 以及直辖市作为金融集聚水平测度的对象, 样本区 间设定为 2001-2012 年。原始数据来源于《中国统 计年鉴》、《中国金融年鉴》、《中国保险年鉴》、《中 国证券期货统计年鉴》各个地区的统计年鉴、年度 统计公报、金融运行报告、中经网数据库以及国泰 君安金融数据库等。鉴于原始数据数量较大, 文中 就不再一一详细列示。

\section{3. 主成份分析方法简介}

目前我国国内关于金融集聚水平的研究大多 采用了三种较为主流的方法依次分别是: 层次分析 法、主成分分析法和因子分析法，本文从三种方法 的适用性出发, 结合研究的实际问题, 采用主成份 分析法进行分析。

主成分分析法的原理就是将多个指标转换成 能够代表绝大多数信息的少数几个指标 (主成份), 并且提取出来的指标之间没有相关性，各自保持独 立, 以此来达到降低维度和简化数据的目的。

模型基本原理如下 ${ }^{[12]}$ :

假设有 $n$ 个样本，测得 $p$ 项指标。得到原始数 据阵: $X=\left(X_{1}, X_{2}, \ldots, X_{P}\right)$, 且协方差阵为 $\Sigma$, 令协 方差阵的特征根值为 $\lambda_{1} \geq \lambda_{2} \geq \cdots \geq \lambda_{p}$, 所以有
$\operatorname{Var}\left(F_{1}\right) \geq \operatorname{Var}\left(F_{2}\right) \geq \cdots \geq \operatorname{Var}\left(F_{P}\right) \geq 0$, 向量 $l_{1} l_{1}, \cdots l_{p}$ 为相应的单位特征向量, 则 $X$ 的第 $i$ 个主成份为:

$$
Z_{i}=l_{i}^{\prime} X \quad(i=1,2, \cdots, p)
$$

实际问题中往往协差阵 $\Sigma$ 未知, 这时可以用其 估计值 $S$ (样本协差阵) 来代替。为了解决指标体 系中各个指标量纲不同的问题, 在计算之前需要对 原始化的数据进行一个标准化的处理以便于使其 之间具有可比性, 此时:

$$
S=R=\frac{1}{n} X^{\prime} X
$$

一般按累计贡献率的大小提取主成份, 多数情 况下取出前 2-3 个主成份已包含了 $90 \%$ 以上的信息, 其他的可以忽略不计。

主成份分析通常包括以下几个步骤:

(1) 对原来的 $\mathrm{n}$ 个指标进行标准化, 以消除 各个变量在数量级或量纲上的影响;

（2）根据标准化后的数据求出协方差或相关 矩阵;

（3）求出协方差矩阵的特征根和特征向量;

（4）确定主成份, 并根据因子载荷矩阵对主 成份的经济含义进行解释说明;

（5）计算主成份的得分, 以此进行最后的判 断。

\section{4. 实证分析}

本文运用 SPSS 21.0 统计软件, 对西部 11 个地 区 2001-2012 年 12 年的数据进行主成份分析, 并最 终计算出每个地区主成份的综合得分, 如表 2 所示。

根据表 2 中综合得分 $\mathrm{F}$ 值的大小, 对 11 个地 区每年的金融集聚程度进行排名, 以此观测 11 个 地区在 12 年时间里金融集聚水平的变化情况, 排 名见表 3 。

从表 3 可以看出, 2001-2012 年 12 个年度内, 11 个地区的金融集聚程度相对比较稳定。整体来看, 四川省的金融集聚水平为最高, 接下来依次是陕西、 重庆、内蒙古、云南、新疆、广西、甘肃、贵州、 宁夏、青海。可见自西部大开发以来我国对四川、 陕西、重庆、内蒙古、云南、新疆、广西等省份提 供了力度较大的金融支持, 尤其是四川、陕西、重 庆三个相邻的省份, 形成了明显的金融辐射效应。 一方面, 由于这几个地区发展的比较早, 经济基础 相对于其他几个地区来说更加殷实; 
Risk Analysis and Crisis Response in Big Data Era (RAC-16)

表 2 2001-2012 年西部 11 个地区金融集聚水平综合得分

\begin{tabular}{|c|c|c|c|c|c|c|c|c|c|c|c|c|c|}
\hline 省份 & 2001 年 & 2002 年 & 2003 年 & 2004 年 & 2005 年 & 2006 年 & 2007 年 & 2008 年 & 2009 年 & 2010 年 & 2011 年 & 2012 年 & 均值 \\
\hline 重庆 & 0.2737 & 0.3457 & 0.3183 & 0.2910 & 0.2247 & 0.2772 & 0.3985 & 0.3982 & 0.2962 & 0.4906 & 0.4604 & 0.3976 & 0.35 \\
\hline 四川 & 2.1199 & 2.1057 & 2.1297 & 2.1086 & 2.1970 & 2.2102 & 2.2059 & 2.2329 & 2.2134 & 2.3073 & 2.3215 & 2.3209 & 2.21 \\
\hline 贵州 & -0.6488 & -0.7173 & -0.6972 & -0.6256 & -0.6016 & -0.5597 & -0.4348 & -0.5697 & -0.5435 & -0.5489 & -0.5194 & -0.5135 & -0.58 \\
\hline 云南 & 0.3778 & 0.2650 & 0.2349 & 0.1878 & 0.0938 & 0.1390 & 0.2893 & 0.1550 & 0.1398 & 0.0687 & 0.0350 & -0.0033 & 0.17 \\
\hline 陕西 & 0.4046 & 0.4689 & 0.4877 & 0.6003 & 0.5972 & 0.5715 & 0.5867 & 0.5229 & 0.4602 & 0.4357 & 0.4755 & 0.4470 & 0.50 \\
\hline 甘肃 & -0.4506 & -0.3020 & -0.2939 & -0.3377 & -0.3703 & -0.3938 & -0.2640 & -0.4189 & -0.4859 & -0.4067 & -0.4519 & -0.4383 & -0.38 \\
\hline 青海 & -1.0628 & -1.1070 & -1.1626 & -1.2761 & -1.2861 & -1.3051 & -1.0750 & -1.2502 & -1.1983 & -1.1647 & -1.2062 & -1.1967 & -1.19 \\
\hline 宁夏 & -0.9766 & -0.9537 & -0.9171 & -0.8980 & -0.7754 & -0.8057 & -0.6959 & -0.9022 & -1.0204 & -0.8508 & -0.8665 & -0.8532 & -0.88 \\
\hline 新疆 & 0.1542 & 0.2079 & 0.2676 & 0.1524 & 0.0761 & 0.0446 & 0.1582 & -0.0082 & -0.2676 & -0.1061 & -0.1297 & -0.0801 & 0.04 \\
\hline 内蒙 & -0.1574 & -0.2729 & -0.2940 & -0.1453 & -0.1110 & -0.0876 & 0.1623 & 0.0221 & 0.4423 & -0.0659 & 0.0439 & 0.0285 & -0.04 \\
\hline 广西 & -0.0339 & -0.0403 & -0.0732 & -0.0575 & -0.0445 & -0.0905 & 0.0474 & -0.1819 & -0.0363 & -0.1591 & -0.1626 & -0.1089 & -0.08 \\
\hline
\end{tabular}

表 3 2001-2012 年西部 11 个地区金融集聚水平排名

\begin{tabular}{|c|c|c|c|c|c|c|c|c|c|c|c|c|}
\hline 省份 & $\begin{array}{c}200 \\
1 \text { 年 }\end{array}$ & $\begin{array}{c}2002 \\
\text { 年 }\end{array}$ & $\begin{array}{c}2003 \\
\text { 年 }\end{array}$ & $\begin{array}{c}2004 \\
\text { 年 }\end{array}$ & $\begin{array}{c}2005 \\
\text { 年 }\end{array}$ & $\begin{array}{c}2006 \\
\text { 年 }\end{array}$ & $\begin{array}{c}2007 \\
\text { 年 }\end{array}$ & $\begin{array}{c}2008 \\
\text { 年 }\end{array}$ & $\begin{array}{c}2009 \\
\text { 年 }\end{array}$ & $\begin{array}{c}2010 \\
\text { 年 }\end{array}$ & $\begin{array}{c}2011 \\
\text { 年 }\end{array}$ & $\begin{array}{c}2012 \\
\text { 年 }\end{array}$ \\
\hline 重庆 & 4 & 3 & 3 & 3 & 3 & 3 & 3 & 3 & 4 & 2 & 3 & 3 \\
\hline 四川 & 1 & 1 & 1 & 1 & 1 & 1 & 1 & 1 & 1 & 1 & 1 & 1 \\
\hline 贵州 & 9 & 9 & 9 & 9 & 9 & 9 & 9 & 9 & 9 & 9 & 9 & 9 \\
\hline 云南 & 3 & 4 & 5 & 4 & 4 & 4 & 4 & 4 & 5 & 4 & 5 & 5 \\
\hline 陕西 & 2 & 2 & 2 & 2 & 2 & 2 & 2 & 2 & 2 & 3 & 2 & 2 \\
\hline 甘肃 & 8 & 8 & 7 & 8 & 8 & 8 & 8 & 8 & 8 & 8 & 8 & 8 \\
\hline 青海 & 11 & 11 & 11 & 11 & 11 & 11 & 11 & 11 & 11 & 11 & 11 & 11 \\
\hline 宁夏 & 10 & 10 & 10 & 10 & 10 & 10 & 10 & 10 & 10 & 10 & 10 & 10 \\
\hline 新疆 & 5 & 5 & 4 & 5 & 5 & 5 & 6 & 6 & 7 & 6 & 6 & 6 \\
\hline 内蒙 & 7 & 7 & 8 & 7 & 7 & 6 & 5 & 5 & 3 & 5 & 4 & 4 \\
\hline 广西 & 6 & 6 & 6 & 6 & 6 & 7 & 7 & 7 & 6 & 7 & 7 & 7 \\
\hline
\end{tabular}

另一方面, 这些地区具有丰厚的自然资源储备, 比 如, 内蒙古与陕西的已探明的煤存量仅次于山西; 新疆作为 “西气东输” 的重要源头拥有占全国 $22 \%$ 总量的天然气资源。

\section{5. 结束语}

西部地区因其特殊的地理位置，导致了该区域 在未来经济的发展过程中, 应充分认识到自身存在 的优劣势, 扬长避短。

优势：西部省域中靠近中部边缘的几个地区， 像陕西、内蒙古、贵州, 与中部地区相接, 虽然经 济发展水平不如中东部地区, 但却有着宝贵的自然 资源, 比如矿产、自然景观, 通过自己的优势产业 加强与中东部地区的经济往来, 经济贸易额扩大了, 金融机构就会自发的进驻这些地区, 继而将这种金 融资源向更边远的西部省份疏导, 以点带面, 带动 整个西部地区经济、技术等各方面的进步与完善。
劣势: 我国西部省域金融集聚程度不高主要劣 势在于基础设施的落后。一方面, 由于信息技术的 滞后, 导致我国西部地区企业的运营效率及产品创 新落后; 另一方面, 交通运输的不便利制约了其与 外界的交易。因此, 这些地区资金的流通速度不高、 融通规模不大, 集聚程度也较低。此外, 受不发达 的经济发展水平的制约, 我国西部省域的三大产业 发展十分不均衡, 作为经济发展基础的农业种植规 模低, 工业水平落后, 服务业还尚待开发。

根据各个省份不同年份的综合得分及排名情 况, 可以把这些研究对象分为两类。一类是金融集 聚水平较高的省份, 分别是四川、陕西、重庆、内 蒙古、云南、新疆、广西等 7 个省份; 另一类是金 融集聚水平较低的省份, 分别是甘肃、贵州、宁夏 和青海。可以发现, 金融集聚的区位效应显著; 邻 近中部的西部省市以四川、陕西、重庆为代表金融 集聚水平较高; 另外, 自然资源在金融集聚过程中 
Risk Analysis and Crisis Response in Big Data Era (RAC-16)

也起到了至关重要的作用, 像内蒙古、新疆等地的 矿产资源，云南、广西等地的旅游资源，都在一定 程度上促使了金融的集聚。而其他一些距离中部省 份较远的地区如宁夏和青海等, 因其在环境、交通 和气候等条件方面都相对比较不利, 因此这些地区 的金融集聚水平普遍较低。

因此，为了提高我国西部省域整体的金融集聚 水平，应该结合前面对于西部地区金融集聚优劣势 的分析, 结合不同地区的特点, 构建差异化的发展 模式, 挖掘地区发展的潜在优势, 提高地区金融集 聚水平。

\section{参考文献:}

[1] G.P. Swann, S.O. Prevezerm. The Dynamics of Industrial Clustering:International Comparisons in Computing and Biotechnology. Oxford: Oxford University Press, 1998:67-73.

[2] N.R. Pandit, G.A.S. Cook, P.G.M. Swann. The dynamic of industrial clustering in British financial services. The Service Industrial Journal, 2001, 21 (4):33 - 61.
[3]王力,周波.金融中心建设与地区经济增长的相关问 题研究.中国城市经济, 2004(6):37-40.

[4]梁颖.金融产业集聚的宏观动因. 南京社会科 学,2006,(11): 56-62.

[5]刘军, 黄解宇, 曹利军. 金融集聚影响实体经济机制研 究.管理世界, 2007(4): 152-153.

[6]黄解宇. 金融集聚研究综述.工业技术经 济,2008,(1):142-146.

[7]滕春强. 金融企业集群发展动因研究.上海金 融,2006,(5):14-17.

[8]王步芳.基于产业集群的首都金融业发展策略探讨. 北京市财贸管理干部学院学报,2006,34(4):23-27.

[9] 马丹.金融集聚浅析以及金融产业集聚程度评价指 标体系的实证研究.泉州:华侨大学,2007.

[10]丁艺, 李树丞, 李林.中国金融集聚程度评价分析. 软 科学, 2009,23(6):9-13.

[11] 李静,白江. 我国地区金融集聚水平的测度. 求是学 刊, 2014,41(4):52-58.

[12] H.M. Zhang, Y.Z. Chen, Z. Wang. Research on the performance evaluation of government venture capital fund based on factor analysis and DEA model. Journal of Risk Analysis and Crisis Response, 2016, 6(1): 15-20. 